\title{
Dynamics on Distribution, Production, and Biological Interactions of Pacific Salmon in the Changing Climate of the North Pacific Ocean
}

\author{
Masahide Kaeriyama \\ Arctic Research Center, Hokkaido University, N21 W11, Kita-ku, Sapporo Japan
}

Keywords: Pacific salmon, global warming, inter-specific interaction, intra-specific interaction, trophic level, population density-dependent effect

The global warming effect for the distribution of chum salmon based on the IPCC AR4 SRES-A1B scenario was already predicted (Kaeriyama 2008), and it was clarified that Japanese chum salmon were positively affected in the 1990s (Kaeriyama et al. 2012, 2014) and negatively influenced since the mid-2000s by global warming (Kaeriyama and Urabe 2018; Kaeriyama 2019). Global warming will have significant impacts on the distribution and migration of Pacific salmon in the North Pacific in this century. The objective of this paper is to evaluate the global warming effect on distribution, production, and inter- and intra-specific interactions of Pacific salmon in order to establish sustainable salmon conservation management. The COBE-SST database of the Japan Meteorological Agency was used to evaluate the SST in the North Pacific Ocean and Arctic Sea, the stable isotope analysis for evaluating the trophic level of Pacific salmon, and the Lotka-Volterra equations for evaluating the interand intra-specific interactions among pink, sockeye, and chum salmon. I also defined optimal (OGT) and allowable growth temperatures (AGT) of chum salmon as $8-12{ }^{\circ} \mathrm{C}$ and $5-7^{\circ} \mathrm{C}$, respectively (Kaeriyama 2004; Kaeriyama and Urabe 2018).

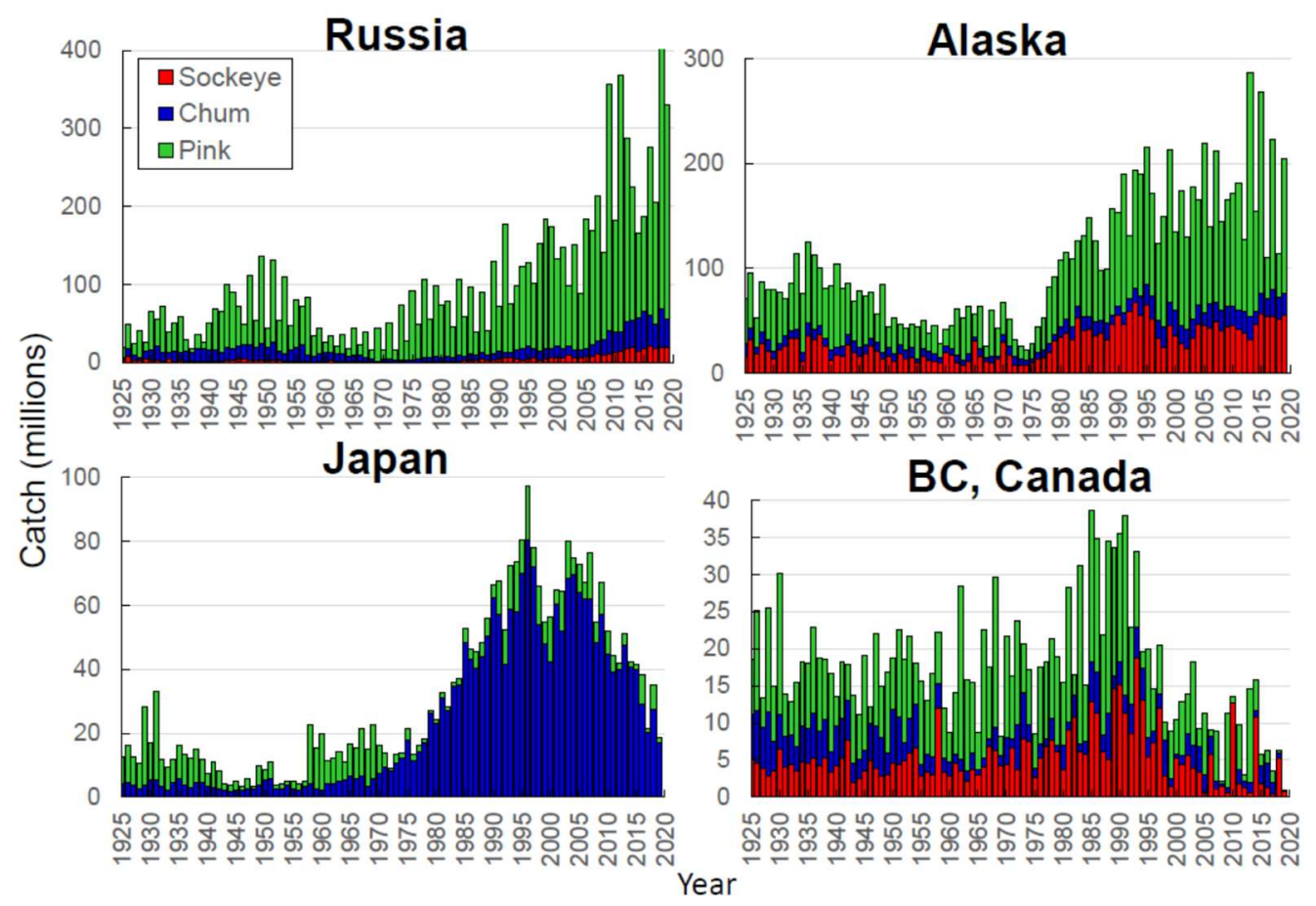

Fig.1. Annual changes in catch of pink, chum, and sockeye salmon in 1925-2019 in the North Pacific Ocean (Data: NPAFC Catch Statistics).

Based on the NPAFC catch data of pink, chum, and sockeye salmon in the North Pacific Ocean (Fig. 1), the southern salmon catch has followed a decreasing trend in Japan since the mid-2000s and in British Columbia, Canada, since the 1990s. In contrast, northern salmon abundance has trended upwards in Russia since the mid2000s and has been highly stable in Alaska since the 1990s. Temporal changes in areas of AGT and OGT of chum salmon in June and July from the 1920s to the 2010s in the North Pacific Ocean and the Arctic Sea indicate the following:

1) In June, the area of AGT has increased since the 1980s, and approached almost all coasts of Russia in the 2010s, coinciding with increased abundance and survival rate during the early ocean-life period of Russian chum 
and pink salmon (Figs. 1, 2). This suggests that Okhotsk and Bering Seas are favorable ecosystems for the survival of Russian chum and pink salmon since the mid-2000s (Kaeriyama 2019).

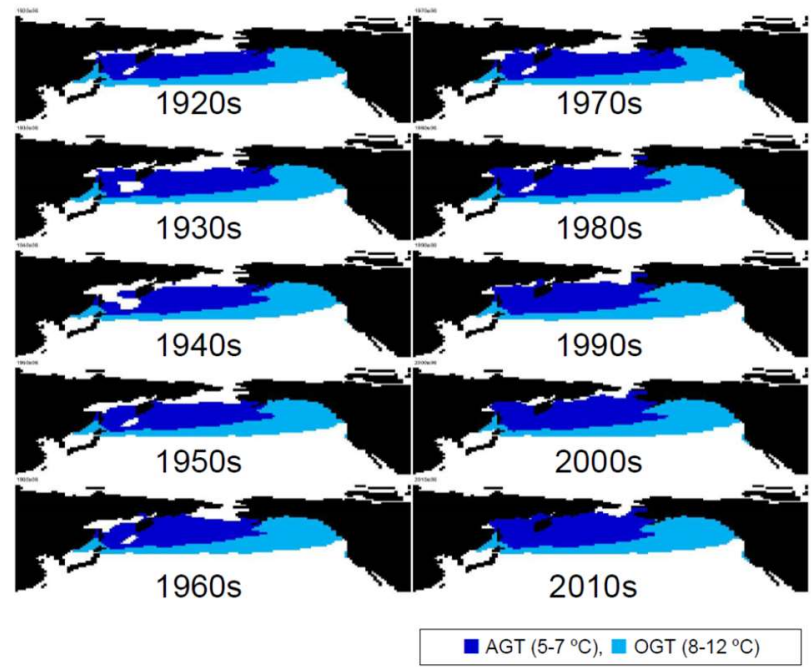

Fig. 2. Temporal change in the allowable growth (AGT) and the optimal growth temperatures (OGT) of chum salmon in June during the 1920s-2010s in the North Pacific Ocean and the Arctic Sea.

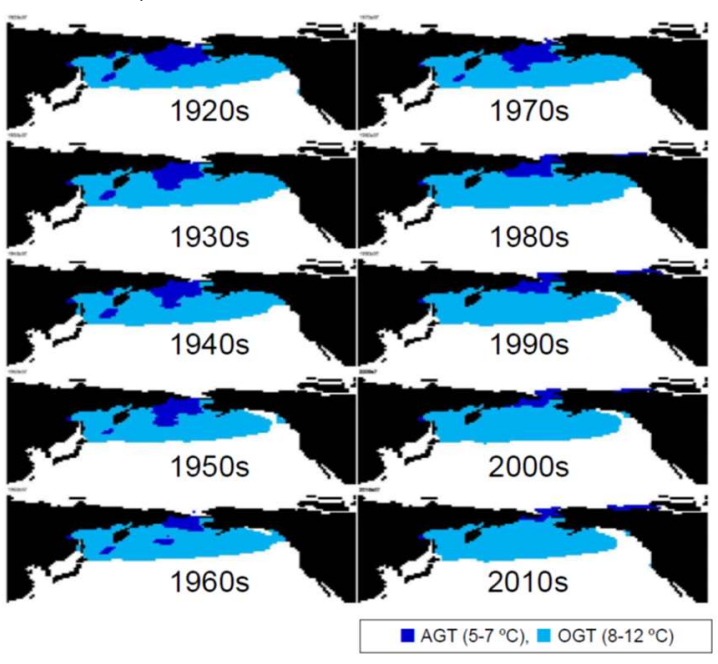

Fig. 3. Temporal change in the allowable growth (AGT) and the optimal growth temperatures (OGT) of chum salmon in July during the 1920s-2010s in the North Pacific Ocean and the Arctic Sea.

2) In July, the area of OGT showed a tendency to leave the coast in the Gulf of Alaska since the mid-1990s and from the waters near Japan in the 2010s. Each of these periods appeared to coincide with the decline of salmon abundance in British Columbia, Canada, and Japan, respectively (Figs. 1, 3). For Fraser River sockeye salmon, communicating uncertainty in fisheries management inputs is increasingly important with climate change, and as ecosystems and fish respond (Cohen 2012; Peterman and Dorner 2012; Grant et al. 2021). On the other hand, Japanese chum salmon would miss a migration route to the Okhotsk Sea and their survival rate has declined since the late-2000s (Kaeriyama and Urabe 2018).

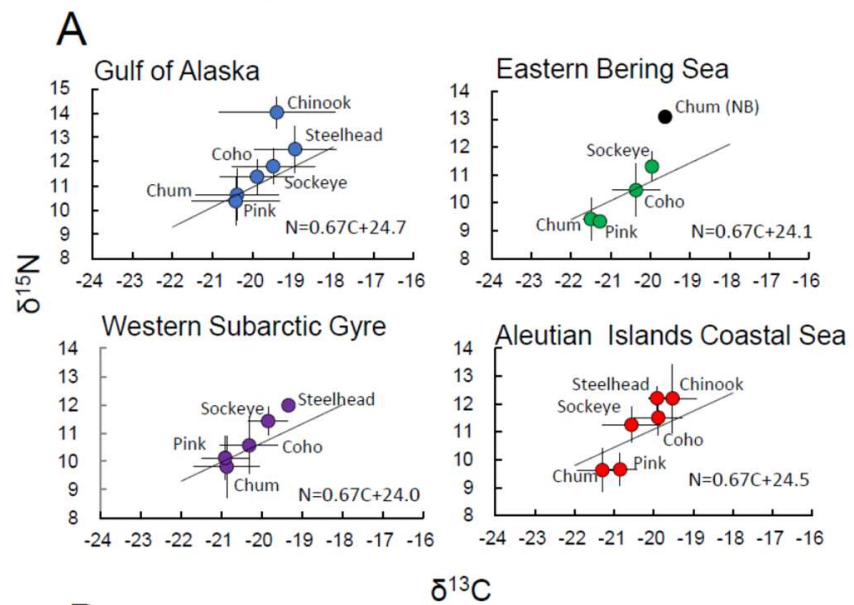

Fig. 4. Mean and SD in $\delta^{13} \mathrm{C}$ and $\delta^{15} \mathrm{~N}(\mathrm{~A})$ and trophic levels (B) of Pacific salmon in the North Pacific Ocean. NB: off the St. Lawrence Island

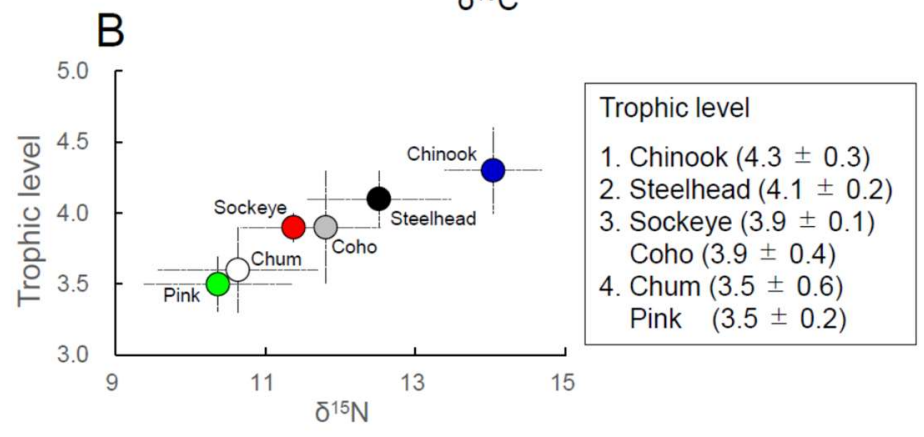


The relationship between $\delta^{13} \mathrm{C}$ and $\delta^{15} \mathrm{~N}$ of Pacific salmon (Fig. 4A) showed parallel regression lines for the Gulf of Alaska, the Western Subarctic Gyre, the eastern Bering Sea, and the coastal sea around the Aleutian Islands in the North Pacific Ocean (ANCOVA; $F=2.283, p=0.059$ ), except for chum salmon off St. Lawrence Island, where they had maximum enrichment because of high nutrient abundance and low growth rate of phytoplankton under a cool climate and strong upwelling environment (Schell et al 1998; Qin and Kaeriyama 2016). These common slopes among four ecosystems indicate the kinetic isotope effect (Wada et al. 2013) in the North Pacific Ocean, suggesting that the dynamics of multiple metabolic chain systems are similar for Pacific salmon (Sugisaki et al. 2013). In Pacific salmon, Chinook salmon occupied the highest trophic level (4.3), followed by steelhead trout (4.1), sockeye and coho (3.9), and chum and pink salmon (3.5) (Fig. 4B; Qin and Kaeriyama 2016). The sockeye, chum, and pink salmon had lower trophic levels than other species, despite being more than $95 \%$ of the total catch of Pacific salmon in the North Pacific Ocean.
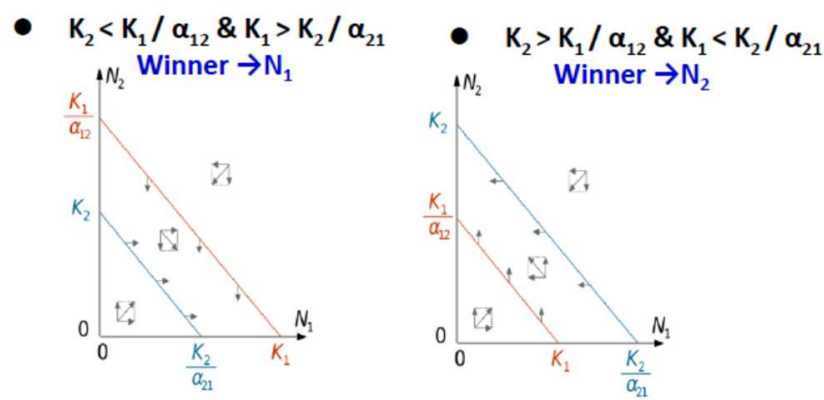

- $K_{2}>K_{1} / \alpha_{12} \& K_{1}>K_{2} / \alpha_{21}$ Winner $\rightarrow \mathrm{N}_{0}: \mathrm{N}_{1}>\mathrm{N}_{2}$
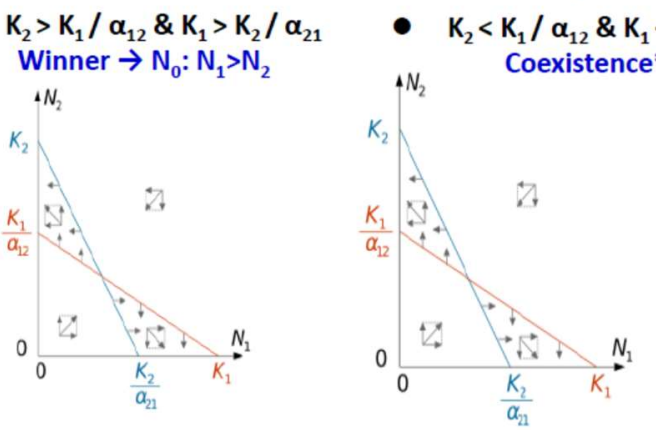

Fig. 5. Loka-Volterra equations of two species $\left(\mathrm{N}_{1}\right.$ and $\mathrm{N}_{2}$ ). K: carrying capacity, $\mathrm{N}$ : population size, $\alpha$ : competition coefficient, 1: species 1,2 : species 2 . * Convergence

I evaluated the inter- and intra-specific interaction of pink, chum, and sockeye salmon using the LotkaVolterra equations (Fig. 5). I used 2010-2018 catch data as population size and 1993-2018 catch data as a carrying capacity for each country's population of the three species. In the three species, pink salmon was strongest, followed by sockeye and chum salmon. No consistent regularity was found for intraspecific interactions (Table 1). Temporal changes in body size and abundance of pink, sockeye, and chum salmon from 2000 to 2018 in the North Pacific Ocean are indicated as follows.

1) Pink and sockeye salmon decreased body sizes with an increase in their abundance, although chum salmon decreased their body size without a change in abundance.

2) Body sizes of the three species had significant negative correlations with the abundance of pink and sockeye salmon, despite no correlation between body sizes and abundance of chum salmon (Fig. 6).

That is to say, the abundance of pink and sockeye salmon would affect the density-dependent effect for three species as the inter- and intra-specific interaction except for chum salmon. 
A
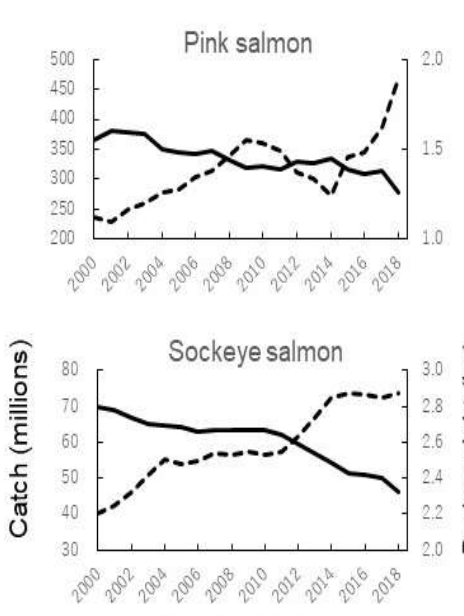

Chum salmon

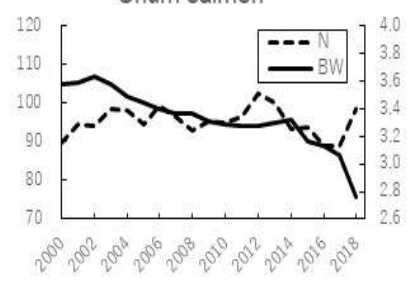

Year
B
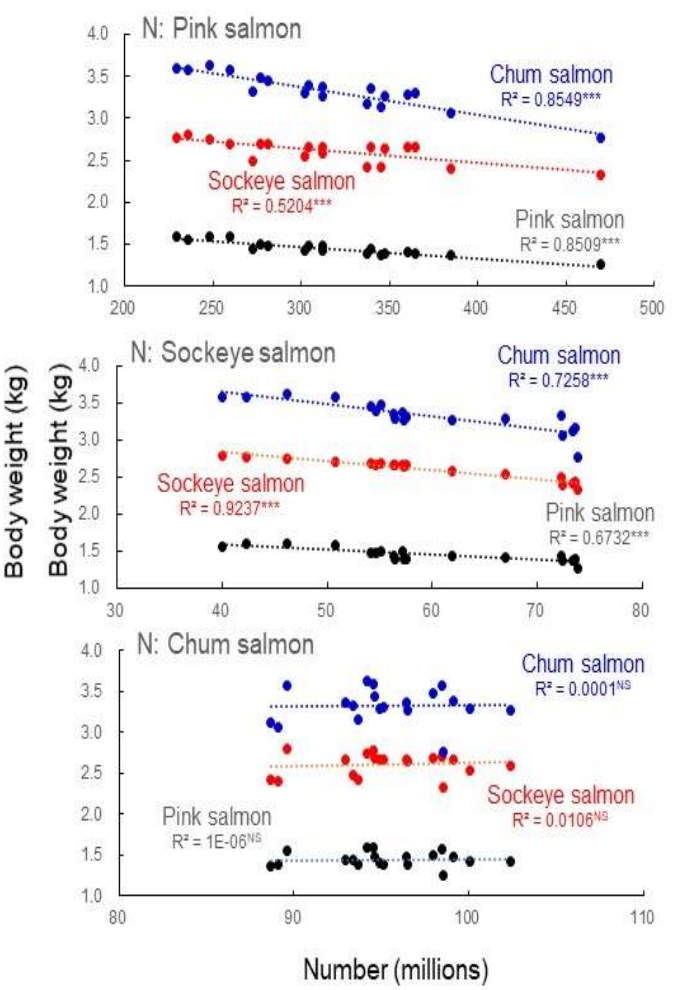

Fig. 6. Density-dependent effect for pink, sockeye, and chum salmon in the North Pacific Ocean. A: Temporal changes in abundance $(\mathrm{N})$ and body size (BW). B: Relationship between abundance and body size for chum, pink and sockeye salmon since 2000. Data: NPAFC Catch Statistics

\section{REFERENCES}

Cohen, B.I. 2012. The uncertain future of Fraser River sockeye. Vol. 1. Commission of inquiry into the decline of sockeye salmon in the Fraser River, Ottawa. 459 pp.

Grant, G.H.S., J. Nener, B.L. MacDonald, J.L. Boldt, J. King, D.A. Patterson, K.A. Robinson, and S. Wheeler. 2021. Canadian Fraser River sockeye salmon: a case study. In Adaptive management of fisheries in response to climate change. Edited by T. Bahri, M. Vasconcellos, D. Welch, J. Johnson, R.I. Perry, X. Ma and R. Sharma. FAO, UN. pp. 259-284.

Kaeriyama, M. 2004. Population ecology of chum salmon. In The ecology and evolution of salmonids. Edited by K. Maekawa. Bunichi-sogoshuppan, Tokyo. pp. 137-163. (In Japanese)

Kaeriyama, M. 2008. Ecosystem-based sustainable conservation and management of Pacific salmon. In Fisheries for Global Welfare and Environment. Edited by K. Tsukamoto, T. Kawamura, T. Takeuchi, T.D. Beard, Jr. and M.J. Kaiser. TERAPUB, Tokyo. pp. 371-380.

Kaeriyama, M. 2019. Sustainable conservation and use of chum salmon under warming climate and changing ocean conditions. N. Pac. Anadr. Fish Comm. Tech. Rep. 15: 109-112. (Available at https://npafc.org)

Kaeriyama, M., and Y. Urabe. 2018. Global warming effect for migration route of Japanese chum salmon. N. Pac. Anadr. Fish Comm. Tech. Rep. 11: 91-95. (Available at https://npafc.org)

Kaeriyama, M., H. Seo, H. Kudo, and M. Nagata. 2012. Perspectives on wild and hatchery salmon interactions at sea, potential climate effects on Japanese chum salmon, and the need for sustainable salmon fishery management reform in Japan. Environ. Biol. Fish. 94: 165-177.

Kaeriyama, M., H. Seo, and Y. Qin. 2014. Effect of global warming on the life history and population dynamics of Japanese chum salmon. Fish. Sci. 80: 251-260.

Peterman, R.M., and B. Dorner. 2012. A widespread decrease in productivity of sockeye salmon (Oncorhynchus nerka) population in western North America. Can. J. Fish. Aquat. Sci. 69: 1225-1260.

Qin, Y., and M. Kaeriyama. 2016. Feeding habits and trophic levels of Pacific salmon (Oncorhynchus spp.) in the North Pacific Ocean. N. Pac. Anadr. Fish Comm. Bull. 6: 469-481. (Available at https://npafc.org) 
Schell, D.M., B.A. Barnett, and K.A. Vinette. 1998. Carbon and nitrogen isotope ratios in zooplankton in the Bering, Chukchi, and Beaufort seas. Mar. Ecol. Prog. Ser. 162: 11-23.

Sugisaki, H., M. Kodama, T. Ichikawa, K. Yamada, E. Wada, and T. Watanabe. 2013. A new aspect on food web analyses using a nitrogen and carbon isotope map-Guidance for interpretations of values and estimation model for stable isotope values of primary producers of food web. J. Fish. Tech. 6: 57-68. (In Japanese with English abstract)

Wada, E., R. Ishii, M.N. Aita, N.O. Ogawa, A. Kohzu, F. Hyodo, and Y. Yamada. 2013. Possible ideas on carbon and nitrogen trophic fractionation of food chains: a new aspect of food-chain stable isotope analysis in Lake Biwa, Lake Baikal, and the Mongolian grasslands. Ecol. Res. 28: 173-181. 